\title{
Toy-mediated distraction: Clarifying the role of distraction agent and preneedle distress in toddlers
}

\author{
Jessica Hillgrove-Stuart MA ${ }^{1}$, Rebecca Pillai Riddell PhD CPsych ${ }^{1,2,3}$, Rachel Horton MA ${ }^{1}$, Saul Greenberg MD FRCPC ${ }^{2,3}$
}

\author{
J Hillgrove-Stuart, R Pillai Riddell, R Horton, S Greenberg. \\ Toy-mediated distraction: Clarifying the role of distraction \\ agent and preneedle distress in toddlers. Pain Res Manag \\ 2013;18(4):197-202.
}

BACKGROUND: Distraction has recently gained attention as a technique that may help reduce acute pain in infants and toddlers; however, results remain equivocal. It appears that these mixed results stem from a variety of methodological differences with regard to how distraction is implemented.

OBJECTIVES: To offer more definitive conclusions regarding the efficacy and mechanisms of distraction for pain management during infancy. Specifically, the goal was to examine whether the agent of distraction (ie, the specific person conducting the distraction) and preneedle distress behaviours impact the efficacy of distraction when toddlers were held by parents.

METHODS: A total of 99 toddlers were randomly assigned to one of three conditions (typical care, research assistant-directed distraction or parentdirected distraction). Toddler distress behaviours were assessed pre- and postneedle. Toddlers were further grouped according to distress behaviours preneedle (low/no distress versus high distress). Parental soothing behaviours were also assessed as a manipulation check.

RESULTS: Toddler postneedle pain did not significantly differ among groups. However, toddlers who were distressed preneedle displayed significantly more pain postneedle, regardless of the treatment group. There were no significant interactions between treatment group and preneedle distress behaviours.

CONCLUSIONS: These results suggest that, when being held by a parent, distraction using a toy does not result in lower pain scores in the context of immunization, regardless of who offers the distraction. Furthermore, these findings raise the notion that if clinicians ensured toddlers were regulated before attempting an immunization, postneedle pain may be significantly reduced.

Key Words: Distraction; Infant; Pain; Randomized control trial; Toddler

\author{
La distraction par les jouets : clarifier le rôle d'un \\ agent de distraction et du désarroi des tout-petits \\ avant une piqûre
}

HISTORIQUE : La distraction a récemment suscité l'attention comme technique pour contribuer à réduire la douleur aiguë chez les nourrissons et les tout-petits, mais les résultats demeurent équivoques. Il semble que ces résultats mitigés découlent de diverses différences méthodologiques quant à l'exécution de la distraction.

OBJECTIFS : Offrir des conclusions plus définitives au sujet de l'efficacité et des mécanismes de distraction pour prendre en charge la douleur pendant la petite enfance. Notamment, les chercheurs visaient à examiner si l'agent de distraction (c'est-à-dire la personne qui procède à la distraction) et le désarroi avant la piqûre influent sur l'efficacité de la distraction lorsque les tout-petits sont dans les bras de leurs parents.

MÉTHODOLOGIE : Les chercheurs ont réparti aléatoirement un total de 99 tout-petits entre trois méthodes (soins habituels, distraction assurée par un adjoint de recherche ou distraction assurée par un parent). Ils ont évalué les comportements de désarroi des tout-petits avant et après la piqûre. Les tout-petits ont été subdivisés selon leurs comportements de désarroi avant la piqûre (un désarroi faible ou absent par rapport à un désarroi important). Ils ont également évalué les comportements apaisants des parents pour vérifier la manipulation.

RÉSULTATS : La douleur que ressentaient les tout-petits après une piqûre ne différait pas de manière significative entre les groupes. Cependant, les tout-petits qui étaient en désarroi avant une piqûre affichaient beaucoup plus de douleur après la piqûre, quel que soit leur groupe de traitement. Il n'y avait pas d'interactions significatives entre le groupe de traitement et les comportements de désarroi avant une piqûre.

CONCLUSIONS : D'après ces résultats, lorsque le tout-petit est dans les bras d'un parent, la distraction au moyen d'un jouet ne s'associe pas à un indice de douleur moins élevé lors de l'administration d'un vaccin, quelle que soit la provenance de la distraction. De plus, ces résultats laissent croire que si les cliniciens s'assuraient que le tout-petit s'était calmé avant de tenter de lui administrer un vaccin, la douleur après la vaccination pourrait diminuer considérablement.

assistant (RA). Distraction involves the use of materials to provide alternative sensory stimulation during a painful procedure (5). The child's attention is focused on a distractor (eg, a toy) instead of allowing their attention to be focused on the painful stimuli. Distraction is easy to use, inexpensive and has minimal, if any, side effects. This technique has been more widely researched in both older children and adult populations, and many studies have found it to be effective in reducing pain and distress when undergoing acutely painful procedures in these populations (6-8). However, some equivocal findings, even within these older populations, remain (9). In comparison, little research has been performed regarding the use of this technique in toddlers (ie, 12 to 24 months of age), and the research that has been performed is equivocal, with some studies finding support for distraction (10-12) and others not finding support (13-15). It appears that these mixed results stem from a variety of methodological differences with regard to how distraction was implemented in each study. are those that are led by an adult such as a parent, nurse or research

${ }^{1}$ York University; ${ }^{2}$ University of Toronto; ${ }^{3}$ The Hospital for Sick Children, Toronto, Ontario

Correspondence: Ms Jessica Hillgrove-Stuart, The Opportunities to Understand Childhood Hurt Lab, York University, 038J Atkinson Building, Atkinson Department of Psychology, 4700 Keele Street, Toronto, Ontario M3J 1P3. Telephone 416-736-2100 ext 20177, fax 416-736-5662,

e-mail jsh@yorku.ca 
To date, six studies have examined distraction as an intervention in infants and toddlers younger than 24 months of age during immunizations. Based on these studies, a proper synthesis to inform clinical practice is difficult due to the lack of consistency across studies (eg, distractor used, timing of exposure, individual[s] involved in distraction, demonstrated efficacy across or even within research laboratories) and the lack of reporting of specific details regarding the treatment (eg, length of distraction, individual administering the distraction, toddler engagement in distraction, the most effective type of distractor used and the positioning of toddlers during the painful procedure). The majority of studies that found distraction to be effective (10-12) used the Modified Behaviour Pain Scale (MBPS [16]) or the Measure of Adult and Infant Soothing and Distress (MAISD [17]) to measure toddler pain-related distress. The majority of these studies also examined toddler pain-related distress beyond the immediate pain reactivity phase (ie, beyond the first $20 \mathrm{~s}$ after the needle), used video distractors (with or without a toy), always introduced distraction before the immunization, and involved nurses and parents in the distraction. In the studies that did not show distraction to be effective (13-15), only parents were involved, and distraction was either not specifically defined because it represented whatever the parent naturally attempted, or only a toy was provided for the parent to use. An explanation for the equivocal nature of these results is that some studies included a passive distraction technique (eg, the toddler watched a video) or an active distraction technique (the toddler actively manipulated a toy).

Given the lack of systematic attention devoted to the variables surrounding how distraction was implemented, especially when toymediated distraction was used, it is not surprising that equivocal results have been reported. To advance the field, examining the efficacy of distraction tools that are readily available (ie, a toy) to health professionals appears to be most appropriate in terms of translating findings into clinical use. Thus, despite previous findings regarding toys as distractors for toddlers, a toy was chosen over a portable DVD player, which is a less feasible option for many pediatrician offices. Moreover, before moving away from toys as a suitable distractor for toddlers, the role of who is actually using the toy to distract should be examined. The present randomized controlled trial examined the impact of agent of distraction (ie, primary caregiver versus nonprimary caregiver) on the efficacy of distraction for relieving postimmunization pain reactivity and regulation (ie, how distress is regulated after an immunization) in toddlers. The agent of distraction is considered to be a key variable because toddlers are innately driven to achieve closeness to a primary caregiver after a distressing event (18). It follows that having the primary caregiver offer a distractor, instead of focusing on proximally soothing the toddler, may be acting in contrast to the toddler's innate need for closeness. The main research goal was to determine whether the agent of distraction impacts the effectiveness of toy-mediated distraction. Thus, the primary research question was: Do typical care, RA-directed toy distraction, and parent-directed toy distraction conditions have a differential impact on toddler pain reactivity and regulation? It was hypothesized that toddlers in the RA-directed distraction group would have the lowest pain response reactivity and regulation postimmunization because parents could focus on holding their toddler close while someone else distracted their toddler, rather than having to multitask by simultaneously soothing and distracting their toddler.

To clearly address the role of our independent variable (ie, the agent of distraction), the present study controlled each experimental condition, taking into account factors such as timing of exposure, length of distraction and toddler position during the procedure. Furthermore, because parents naturally engage in a variety of other soothing behaviours during painful procedures, other naturally occurring soothing behaviours were also examined in all groups to help contextualize the primary findings.

Finally, preneedle distress behaviours were also examined as a contextual factor that may impact toddlers' pain responses postneedle. Notably, some researchers have postulated that anticipatory distress may prevent young children (one to seven years of age) from fully engaging in distraction (15), yet 'baseline' rates of toddler distress have been ignored in the literature investigating distraction as a pain management strategy. Research from our laboratory has also shown that preneedle distress behaviours are associated with higher pain reactivity scores postneedle (19). Therefore, the second research question that was examined was whether preneedle distress behaviours impact the effectiveness of distraction.

By building on research to date and addressing many of the methodological issues of previous research, the current study aimed to move the field forward to more definitive conclusions regarding the efficacy and mechanisms of distraction for pain management during infancy.

\section{METHODS}

\section{Participants and setting}

Approval to conduct the present study was obtained through both the Human Participants Review Committee at York University and the Hospital for Sick Children's Research Ethics Board (Toronto, Ontario). In the present study, parent-toddler dyads were recruited from a pediatrician's clinic in Toronto. Inclusion criteria for each dyad required that the parent be the primary caregiver of the toddler and be fluent in English; toddlers had to have been brought to the clinic for a scheduled routine immunization and had to be between 12 and 20 months of age. To control for factors that are known to impact toddlers' responses to pain, toddlers with suspected cognitive impairment or chronic illness and toddlers who had been hospitalized or were born before 36 weeks' gestation were ineligible to participate.

\section{Power analysis}

A power analysis conducted before data collection using a medium effect size of 0.54 (which was obtained from previous research evaluating distraction for toddler pain [12]) indicated that 40 participants in each of the three treatment groups would yield a power ranging from 0.80 to 0.99 (depending on the value of the interclass correlation for repeated measures) with a $3 \times 3$ mixed ANOVA design (alpha=0.05) When the same analysis was performed using a sample size of 30 participants in each condition, the power ranged from 0.60 to 0.98 (again, depending on the interclass correlation for repeated measures). Based on these calculations, a sample size of between 30 and 40 toddlers per condition would yield adequate power.

\section{Apparatus}

One video camera was placed on a tripod and captured toddler, parent and RA behaviour. The distractor that was used was an age-appropriate handheld toy (Activity Center, Tiny Love, Israel) that incorporates several modes of processing (ie, visual, auditory and tactile). Accordingly, it allowed for active participation on behalf of the toddler (ie, buttons to press and wheels to spin). However, there were also more passive elements of the toy (ie, music and bright colours) that could engage the toddler if he or she did not actively interact with it. Regardless of condition (ie, RA-directed distraction or parent-directed distraction), the RA held the toy in a manner to maximize toddler access and strictly control toy exposure.

\section{Procedure}

On arrival at the clinic, parents of toddlers 12 to 20 months of age who were receiving a routine immunization were offered a flyer by the clinic receptionist indicating that a study was being performed at the clinic. If the parent stated that they wanted to hear more about the study, an RA approached them and informed them of the study in greater detail. If the parent agreed to participate, they signed the consent forms. The RA then opened an envelope with the subject's identification number on the front, which contained a slip of paper indicating the randomly assigned condition ( 1 = typical care, 2 = RA-directed distraction, 3 = parent-directed distraction). Once this was determined, the RA read the specified script for that particular condition to the parent. An RA blinded to the purpose and hypotheses of the study and who did not partake in collecting and analyzing the data generated the 
allocation sequence using a computerized random number generator. RAs collecting the data could not be blinded to group assignment because each condition required specific instructions and different tasks to be performed. However, all RAs collecting data were blind to the hypotheses of the study. The RAs who directed the distraction were trained psychology undergraduates.

Parents and toddlers first underwent a routine checkup with the pediatrician. The RA then entered the room and began videotaping the dyad from immediately before the immunization(s) until the dyad left the clinic room. Routine procedure in the clinic dictated that parents held their toddler for the immunization; thus, all toddlers were held. After the procedure, parents were asked to complete a brief demographic information form.

\section{Description of conditions}

Typical care: In this condition, parents held their toddler and were asked to interact with their toddler as they normally would; parents were not given a toy or trained on any specific distraction technique.

RA-directed distraction: While parents were holding their toddler, the RA informed the parent that, immediately before the immunization, the RA would be holding a toy and trying to encourage the toddler to attend to it. The parent was specifically instructed not to help the RA engage the toddler and to focus on behaving "as they normally would" with their toddler. RAs were instructed on how to use the toy (ie, spin wheels, press certain buttons to get music to play) as well as how to engage the toddler with the toy using verbal cues (eg, "Look at this!"). The RA was instructed to engage the toddler with the toy starting immediately when the doctor began preparing the toddler by swabbing the injection site with alcohol and to continue for one push of the music button (approximately $45 \mathrm{~s}$ ). This was performed to control the application of the intervention for each toddler, while providing the toddler with distraction before, during and after the needle(s). Introducing the toy immediately before the immunization was chosen to optimize the effect of the novelty of the toy and minimize the possibility of habituation to the toy before the procedure. The RA was instructed to maintain the same level of distraction throughout the 45 s period.

Parent-directed distraction: In this condition, parents were also holding their toddler. To strictly control the intercondition differences, the RA was again holding the toy, but the parent was responsible for encouraging the toddler to attend to it. Moreover, the parents were trained to use the toy in the same way the RAs were trained. They were informed of all the functions of the toy, given suggestions on how to engage their infant, and were told when to begin distracting the toddler and when to stop distracting (ie, when the doctor swabbed the site with alcohol and when the music played through once, approximately $45 \mathrm{~s}$ ).

\footnotetext{
Measures

Demographic questionnaire: Parents were asked to complete a brief demographic questionnaire regarding personal information about themselves (eg, age, sex, cultural background), as well as information about the toddler (eg, age, sex, previous number of injections). When in a distraction condition (either RA-directed or parent-directed), parents were also asked whether their toddler had ever played with the specific toy used in the present study ( $8.3 \%$ of the total sample had seen the toy before). Although controlling which immunizations toddlers received was not possible, the type of immunization received was recorded to determine whether there were group differences with regard to this variable. The majority of toddlers across conditions received two needles during their appointment (typical care: $85 \%$, parent-directed distraction: $97 \%$, and RA-directed distraction: $94 \%$, respectively). Group differences with regard to demographic data are discussed in the results section.

The MBPS: The MBPS (16) was used to assess the degree of toddler pain and distress. The MBPS has been shown to be a valid and reliable measure of acute pain-related distress. There are three subsections of
}

the scale (facial expression, cry and body movement), each requiring the coder to rate overt toddler behaviours during a $15 \mathrm{~s}$ epoch. Facial expression and body movements were scored using a scale from 0 to 3 ( 0 being smiling or relaxed body movements). Cry was scored on a scale from 0 to 4 ( 0 being laughing or cooing to 4 being full-lunged cry in which the toddler is already crying before needle). When complete, all three sections of the measure were summed to obtain a total toddler pain score (range 0 to 10 ) for each of the three phases of immunization.

In the current study, the MBPS was used to code distress during three $15 \mathrm{~s}$ time periods: $15 \mathrm{~s}$ directly preceding the swabbing of the injection site with alcohol (baseline phase); $15 \mathrm{~s}$ directly after the last needle (immediate phase; begins when the needle is inserted); and then again for a $15 \mathrm{~s}$ period at $1 \mathrm{~min}$ after the last needle (recovery phase). The primary coder was blinded to the study hypotheses. Interrater reliability was conducted with a reliability coder. Reliability was high, with interclass correlations ranging from 0.89 to 1.00 in $28 \%$ of the total sample.

The distribution of toddler MBPS distress scores at baseline was examined and it was observed that approximately one-half of the sample exhibited distress behaviours preneedle ( $40.8 \%$ with a score of 3 to 9) and approximately one-half of the sample did not exhibit distress behaviours preneedle ( $59.2 \%$ with a score of 2 or below). Toddlers were divided into two groups according to this natural split: those who displayed behavioural distress preneedle (assigned a value of 1); and those who displayed minimal to no behavioural distress preneedle (assigned a value of 0 ).

The MAISD: The MAISD (17) is a reliable and valid behavioural observation scale that was developed to evaluate the behaviours of children, parents and nurses during painful pediatric medical procedures. For the purpose of the present study, parental soothing behaviours (distraction, offer toy, offer pacifier, offer food, physical comfort, rocking and verbal reassurance) and RA distraction behaviours were coded as present (1) or absent (0) during $5 \mathrm{~s}$ epochs. The MAISD was used to code these behaviours for two phases: the entire $1 \mathrm{~min}$ period immediately before swabbing of the injection site with alcohol (preimmunization swabbing; $12 \times 5 \mathrm{~s}$ epochs) and the entire $1 \mathrm{~min}$ and $15 \mathrm{~s}$ period immediately after the last needle (postimmunization; $15 \times 5 \mathrm{~s}$ epochs). There were two primary coders (both blinded to study hypotheses) and the percentage agreement between the two was high, ranging from $88 \%$ to $100 \%$ agreement on $20 \%$ of the total sample. Analyses were performed using index scores (ranging from 0 to 1) representing the proportion of $5 \mathrm{~s}$ intervals in which a given behaviour occurred in either the preimmunization swabbing phase or the postimmunization phase.

\section{RESULTS}

Data collection spanned 11 months (August 2007 to June 2008), and the final sample consisted of 99 toddlers (41 female; mean [ \pm SD] age $14.98 \pm 2.88$ months) and their parents (See Figure 1 for CONSORT flow diagram of subjects). Mothers accompanied $87 \%$ of toddlers and fathers accompanied $13 \%$ of toddlers in the entire sample. The sample included participants from a wide range of cultural backgrounds, including Japanese, Greek, Italian, Filipino, Irish and Russian, with $22 \%$ of the sample reporting that the cultural background with which they identified most was Canadian. The majority of parents were married $(87 \%)$ and highly educated (75\% had completed a university degree or higher).

Initially, data management analyses were performed to ensure that the analyses could be conducted as planned. Assumption checking, toy exposure analysis, treatment group equivalency analyses and a treatment integrity analysis were conducted before starting the main analyses.

The primary analyses for the present study were performed using the pain-related distress scores (MBPS) as the dependent variables. Two $3 \times 2$ between-group ANOVAs were conducted to determine whether toddlers' pain-related distress scores significantly differed 


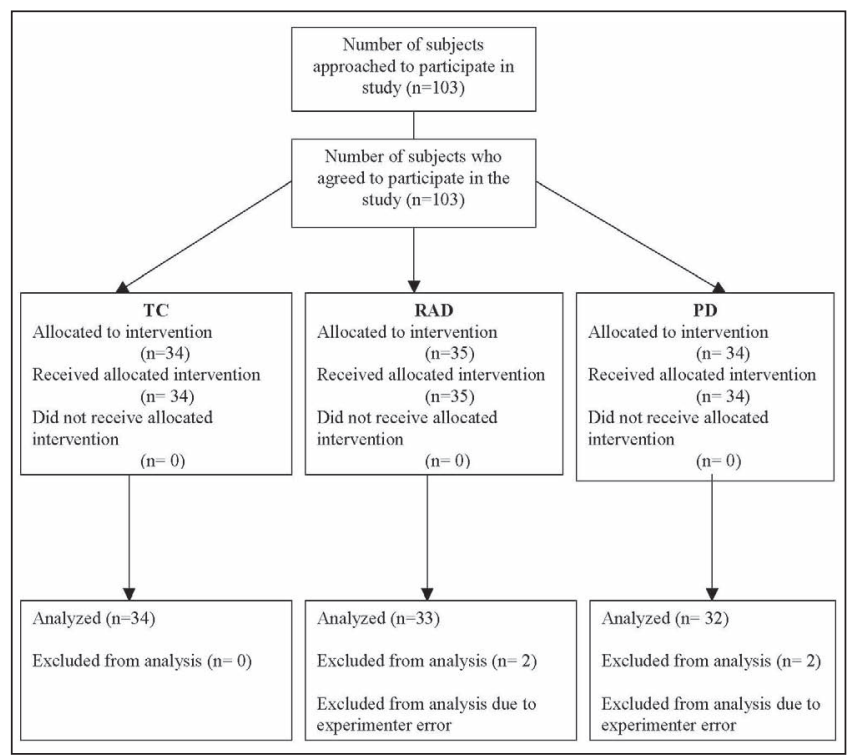

Figure 1) CONSORT Flowchart. PD Parent-directed distraction; RAD Research assistant-directed distraction; TC Typical care

TABLE 1

Mean pain reactivity scores for ANOVA

\begin{tabular}{lcll}
\hline Group & No distress & Distress & \\
\hline Typical care & $7.65 \pm 0.33$ & $9.64 \pm 0.39$ & $8.66 \pm 0.26$ \\
Parent-led distraction & $8.11 \pm 0.34$ & $9.15 \pm 0.41$ & $8.64 \pm 0.26$ \\
RA-led distraction & $8.05 \pm 0.41$ & $9.23 \pm 0.41$ & $8.63 \pm 0.27$ \\
& $7.94 \pm 0.19^{*}$ & $9.34 \pm 0.23^{*}$ & \\
\hline
\end{tabular}

Data presented as mean \pm SE. Main effect means are in shaded cells. *Indicates means that are significantly different $(P<0.0001)$. RA Research assistant

between treatment groups (typical care, RA-directed distraction, parent-directed distraction) and across the two preneedle distress conditions (not distressed preneedle, distressed preneedle). One ANOVA was performed using immediate pain-related distress scores (reactivity) and the second ANOVA used pain-related distress scores 1 min after the final needle (recovery).

Secondary analyses were also performed to contextualize the primary findings. MAISD parental soothing behaviours were examined across treatment groups and phases to obtain a more detailed picture of the soothing behaviours parents were engaging in across conditions and whether there were significant group differences among these variables.

\section{Preliminary analyses}

All assumptions for the planned analyses were verified and met. To examine group equivalency, treatment integrity and impact of previous toy exposure, a conservative $P$ value of 0.05 for each test was used for both ANOVAs and Dunnett's post hoc comparisons. Although significant differences were observed with regard to parent sex, parent age and whether toddlers had received the Prevnar vaccine (Wyeth, USA) during their appointment, post hoc analyses demonstrated no relationship with the pain-related distress outcome measure and, thus, group equivalency was ensured.

In terms of treatment integrity, analyses were conducted to ensure the level of distraction and toddler engagement in distraction varied in the expected directions across the three groups. As expected, level of distraction was significantly higher in both treatment groups than in the control group (with no difference in level of distraction between the two treatment groups). Moreover, the parent-directed distraction group had significantly higher levels of parent-led distraction than the other two groups, and the RA-directed distraction group had significantly higher levels of RA-led distraction than the other two groups.
TABLE 2

Mean pain recovery scores for recovery ANOVA

\begin{tabular}{lcc|c}
\hline Group & No distress & Distress & \\
\hline Typical care & $5.61 \pm 0.53$ & $7.06 \pm 0.64$ & $6.33 \pm 0.41$ \\
Parent-led & $4.72 \pm 0.56$ & $7.08 \pm 0.66$ & $6.47 \pm 0.42$ \\
RA-led & $5.40 \pm 0.53$ & $7.54 \pm 0.66$ & $5.9 \pm 0.43$ \\
& $5.24 \pm 0.312^{*}$ & $7.225 \pm 0.38^{*}$ & \\
\hline
\end{tabular}

Main effect means are in shaded cells. *Indicates means that are significantly different $(P<0.0001)$. RA Research assistant

In addition, there were no significant group differences with regard to the level of toddler engagement in the distraction that was being used.

Finally, the previous level of toy exposure was also examined among the groups and no significant differences were found.

Primary analysis: Toddler pain and distress between treatment groups and baseline distress conditions

Two $3 \times 2$ between-group ANOVAs were performed to determine whether toddlers' pain reactivity and regulation scores significantly differed between treatment groups as well as across baseline distress conditions. There were no main effects of treatment condition on toddler reactivity or regulation distress scores $(F[2,92]=0.001, P=0.999$; $F[2,92]=0.483, P=0.619$, respectively). However, there were main effects for the baseline distress conditions for both toddler reactivity and recovery distress scores $(\mathrm{F}[1,92]=21.86, \mathrm{P}<0.001 ; \mathrm{F}[1,92]=16.45$, $\mathrm{P}<0.001$, respectively). Toddlers who were distressed preneedle had significantly higher pain reactivity and recovery scores (Table 1 and Table 2). There were no significant interactions for either analysis $(F[2,92]=0.990, P=0.376 ; F[2,92]=0.315, P=0.730$, respectively $)$.

Secondary analyses: Parental soothing behaviours across treatment groups and baseline distress scores preneedle

To contextualize the primary findings, two MANOVAs were performed, using all 99 subjects, to better understand the type of nondistraction soothing behaviours used by parents in each condition. For both analyses, offering a toy and offering food were excluded because they occurred less than $10 \%$ of the time. The first analysis examined parental soothing behaviours during the preimmunization swabbing phase. No significant group differences were found among any of the soothing behaviours for this time period. The second analysis examined postimmunization soothing behaviours across conditions. Only one behaviour (verbal reassurance) was found to be significantly different between conditions $(F[2,96]=6.91 ; \mathrm{P}<0.05)$. Post hoc analysis using Dunnett T3 values to control for violations of equality of error variance revealed that parents in the typical care condition made significantly more reassuring comments than did parents in the parent-directed distraction condition $(0.32 \pm 0.23$ versus $0.14 \pm 0.16$; $\mathrm{P}=0.001$ ).

\section{DISCUSSION}

The current study was the first to explore the impact of who is conducting the distraction (ie, the agent of distraction) on the helpfulness of toy distraction for decreasing pain in toddlers who are being held by a parent during routine immunization. Results of the present study suggest that when a parent is holding his or her toddler, distraction with a handheld toy, regardless of whether a parent or nonparent is doing the distraction, is not significantly different than standard care. Because the present study controlled for who led the distraction (parent or RA), the type of toy distractor (ie, one toy that allowed for both passive and/or active participation by the toddler), the amount of toy distraction in each treatment condition (including the onset and duration of distractor), the level of toddler engagement in distraction across conditions, the positioning of the toddler and parent (toddler held proximally in the parent's arms) and both distracting and nondistracting parental soothing behaviours, we assert confidence in these results. 
Our results are consistent with the findings of Jahromi et al (13), Cramer-Berness and Friedman (14), and MacLaren and Cohen (15), and contradict other studies by Cohen $(10)$ and Cohen et al $(11,12)$. There were many key factors that distinguished the current study from others, as well as factors that were common between our study and others. All studies that found distraction to be helpful were performed using video as the distraction. Specifically, the mode of distraction used by studies supporting the efficacy of distraction was a portable DVD player and a video of a popular television show for children. The majority of studies not supporting the use of distraction, including the current study, used a handheld musical toy or examined the naturally occurring distraction behaviours of parents. We had initially hypothesized that toy-mediated distraction had thus far been shown to be ineffective because the parent was diverted from proximally soothing their child (eg, holding them close, using affectionate behaviours such as kissing or rubbing the pained area) due to the distraction. Given that we ensured all parents were holding their children in both treatment groups and the control group (allowing parents the freedom to use proximal soothing behaviours during distraction), this hypothesis was not supported. It is evident that toy-mediated distraction is not an effective technique for reducing toddler pain related distress following immunization. However, given the evidence supporting the effectiveness of video-mediated distraction on reducing the toddler pain response, it is important to note that distraction, in and of itself, should not be considered an ineffective technique. More research is needed to determine which forms of distraction work best with older toddlers undergoing routine immunization.

It is speculated that the lack of group differences on toddler distress behaviour scores occurred mainly because parents in all conditions were holding and proximally soothing their toddlers. This is supported by the finding that there were no significant differences in the amount of parental holding and other 'contact' soothing behaviours between conditions. Thus, when a parent was given the opportunity to hold their child (and proximally soothe), toy-mediated distraction, regardless of being implemented by a parent or nonparent, was not significantly more effective than standard care.

Furthermore, given that preneedle distress is a common occurrence among toddlers older than 12 months of age, we also examined the impact of whether the toddler was distressed preneedle on the effectiveness of distraction. Pain reactivity and regulation scores were examined separately across each treatment group according to baseline levels of toddler distress behaviours (ie, either distressed or not distressed preneedle). Overall, a main effect was found for preneedle distress with regard to both pain reactivity and regulation scores. Across all treatment groups, toddlers who were distressed preneedle were significantly more distressed immediately after the needle and $1 \mathrm{~min}$ after the needle compared with toddlers who were not distressed preneedle. Replicating previous results from our laboratory (19), this finding suggests that preneedle distress results in higher pain scores immediately postneedle; furthermore, this impact occurs regardless of the presence of toy-mediated distraction. This suggests that, on the whole, giving a needle to a toddler who is already distressed will result in that toddler having higher pain scores postneedle than a toddler who was not distressed preneedle.

Our findings raise the idea that if clinicians made efforts to ensure that toddlers are not distressed before attempting an acutely painful stimulus, postneedle pain may be significantly reduced. It is a commonly held belief that preneedle distress behaviours may be a product of

\section{REFERENCES}

1. Toronto Public Health. Toronto Public Health immunization schedule. <www.toronto.ca/health/immunization_children/ immunization_schedule.htm $>$ (Accessed January 28, 2007).

2. Taddio A, Appleton M, Bortolussi R, et al. Reducing the pain of childhood vaccination: An evidence-based clinical practice guideline. Can Med Assoc J 2010;182:E843-E855.

3. Pillai Riddell R, Racine NM, Turcotte K, et al.

Non-pharmacological management of infant and young child procedural pain. Cochrane Database Syst Rev 2011;(10):CD006275. anticipatory anxiety (ie, by 12 months of age, some toddlers may come to associate the doctor with pain due to repetitive pairing of the two over the year [20]). Thus, based in part on our results, one could extrapolate that better acute pain management for needle pain could not only reduce pain in the short term but also in the longer term because there may be less preneedle/anticipatory distress for future needles (due to less painful past needles), resulting in lower postneedle pain scores. To address preneedle distress, immunizing health professionals may want to first perform all needle preparation in the room because this would allow toddlers to habituate to the health professionals' presence. Second, health professionals should ask parents to hold toddlers close to increase proximity and remind parents that being calm in the period before the needle helps their toddlers to be calm for the needle, which in turn typically results in less preneedle distress. Third, interventions, such as administering sucrose $(21,22)$, breastfeeding $(23,24)$ and using topical anesthetics before the procedure, when feasible $(25,26)$, are wellestablished methods of reducing toddler pain-related distress during painful procedures. If used consistently during immunization, these interventions may prevent, or at least reduce, future conditioned anxiety and distress responses to immunization.

There were a number of limitations to the present study. Aspects of how the toy-mediated distraction was executed may have also contributed to the null findings. Because many young children find any physical contact by a medical professional potentially threatening, waiting until the point of physical contact to begin distraction may have limited the effectiveness of the distraction. Perhaps by introducing the distractor earlier in the visit or by using a different toy preneedle, the toddler may be better able to engage in the distraction, diverting attention away from the doctor and needle. However, future studies must take into account toddler habituation when timing the introduction of the toy, to maximize engagement with the toy and the potential efficacy in pain mediation. It is also important to note that the present study was conducted in a pediatrician's clinic located in an area of Toronto with higher socioeconomic status. Consequently, the results of the current study may not be generalizable to parent-toddler dyads from more socioeconomically disadvantaged areas. We also did not examine whether the toddler was passively or actively engaged with the toy distraction. Further examination of the type of engagement toddlers had with the toy may reveal important differences in pain responses. Finally, it remains unclear whether a more highly trained technician (eg, a child life specialist) would be more effective at distracting toddlers than an RA.

In conclusion, from a clinical perspective, our results suggest that when parents are holding their toddlers, toy-mediated distraction does not reduce pain-related distress, regardless of who the agent of distraction is. Moreover, our secondary analyses suggest that, regardless of whether a toy is used, when toddlers are distressed preneedle, they have higher pain-related distress scores in the immediate pain reactivity phase (ie, $15 \mathrm{~s}$ after the painful stimulus is removed) and the recovery phase (ie, 1 min after the painful stimulus is removed) than toddlers who are not distressed preneedle. Interventions aimed at reducing preneedle distress may prove critical to reducing the distress that both toddlers and caregivers experience as a result of these procedures.

ACKNOWLEDGEMENTS: This project was funded by a SSHRC to Ms Jessica Hillgrove-Stuart and a CIHR New Investigator Award to Dr R Pillai Riddel.

4. Chambers CT, Taddio A, Uman LS, McMurtry CM.

Psychological interventions for reducing pain and distress during routine childhood immunizations: A systematic review. ClinTherapeut 2009;31(Suppl. B):S77-S103.

5. Pillai Riddell RR, Stevens BJ. Pain management in infants. In: Schmidt RF, Willis WD, eds. The Encyclopedia of Pain. New York: Springer Berlin Heidelberg, 2007:31-3.

6. Powers SW. Empirically supported treatments in pediatric psychology: Procedure-related pain. J Pediatr Psychol 1999;24:131-45. 
7. DeMore M, Cohen LL. Distraction for pediatric immunization pain: A critical review. J Clin Psychol Med S 2005;12:281-91.

8. Mitchell LA, MacDonald RAR, Knussen C, Serpell MG. A survey investigation of the effects of music listening on chronic pain. Psychol Music 2007;35:37-57.

9. Leventhal, H. I know distraction works even though it doesn't! Health Psychol 1992;11:208-9.

10. Cohen LL. Reducing infant immunization distress through distraction. Health Psychol 2002;21:207-11.

11. Cohen LL, Bernard RS, McClellan CB, Piazza-Waggoner C, Taylor BK, MacLaren JE. Topical anesthesia versus distraction for infants' immunization distress: Evaluation with 6-month follow-up. Child Health Care 2006;35:103-21.

12. Cohen, LL, MacLaren, JE, Fortson BL, et al. Randomized clinical trial of distraction for infant immunization pain. Pain 2006;125:165-71.

13. Jahromi LB, Putnam SP, Stifter CA. Maternal regulation of infant reactivity from 2 to 6 months. Dev Psychol 2004:40:477-87.

14. Cramer-Berness, LJ, Friedman AG. Behavioral interventions for infant immunizations. Child Health Care 2005;34:95-111.

15. MacLaren JE, Cohen LL. A comparison of distraction strategies for venipuncture distress in children. J Pediatr Psychol 2005;30:387-98.

16. Taddio A, Nulman I, Koren BS, Stevens B, Koren G. A revised measure of acute pain in infants. J Pain Symptom Manag 1995;10:456-63.

17. Cohen LL, Bernard RS, McClellan CB, MacLaren, JE. Assessing medical room behavior during infants' painful procedures: The measure of adult and infant soothing and distress (MAISD). Child Health Care 2005;34:81-94.
18. Bowlby J. Attachment and loss: Retrospect and prospect. Am J Orthopsychiat 1969/1982;52:664-78.

19. Ahola Kohut S, Pillai Riddell RR. Does the Neonatal Facial Coding System discriminate between infants experiencing pain related and non-related distress? J Pain 2009;10:214-20.

20. Taddio A, Shah V, Gilbert-MacLeod C, Katz J. Conditioning and hypersensitivity to pain in newborn infants exposed to repeated heel lances. JAMA 2002;288:857-61.

21. Hatfield LA, Chang K, Bittle M, Deluca J, Polomano RC. The analgesic propertied of intraoral sucrose: An integrative review. Advances in Neonatal Care 2011;11:83-92.

22. Stevens B, Ohlsson A. Sucrose for analgesia in newborn infants undergoing painful procedures. Cochrane Database Syst Rev 2000;(2):CD001069.

23. Shah PS, Aliwalas LI, Shah V. Breastfeeding or breast milk for procedural pain in neonates. Cochrane Database Syst Rev 2006;(3):CD004950.

24. Abdel Razek A, Az El-Dein N. Effect of breast-feeding on pain relief during infant immunization injections. Int J Nurs Pract 2009;15:99-104.

25. Lander JA, Weltman BJ. EMLA and amethocain for reduction of children's pain associated with needle insertion. Cochrane Database Syst Rev 2006;(3):CD004236.

26. O'Brien L, Taddio A, Ipp M, Goldbach M, Koren G. Topical 4\% amethocaine gel reduces the pain of subcutaneous measles-mumpsrubella vaccination. Pediatrics 2004;114:e720-4. 


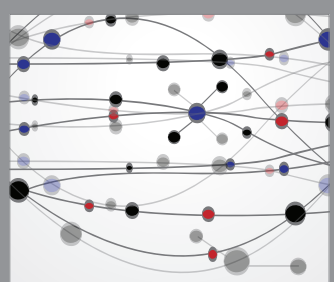

The Scientific World Journal
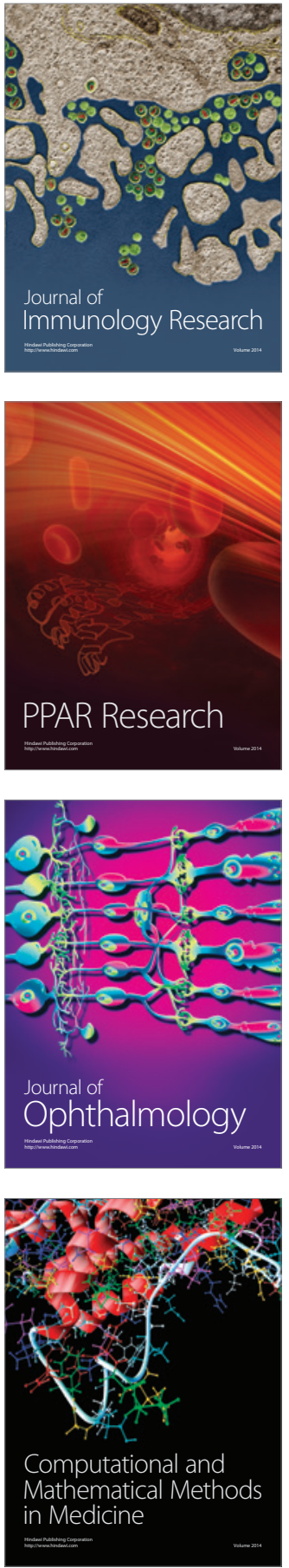

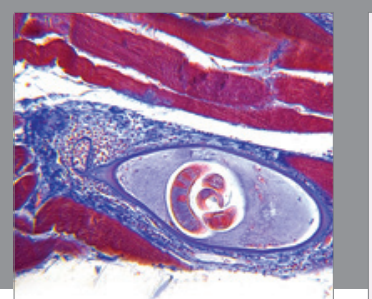

Gastroenterology Research and Practice

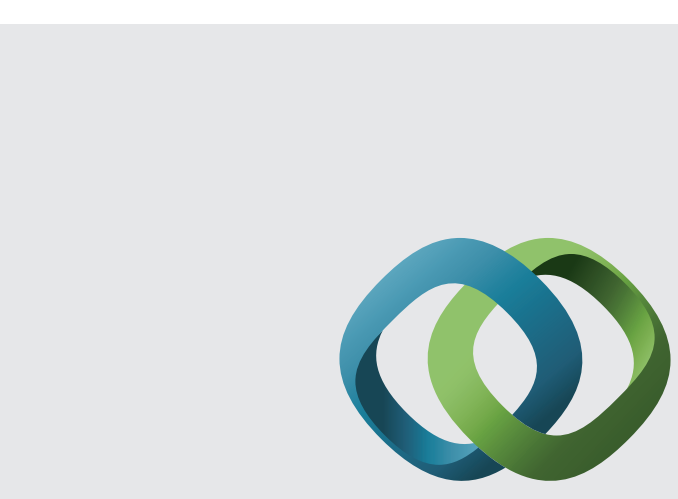

\section{Hindawi}

Submit your manuscripts at

http://www.hindawi.com
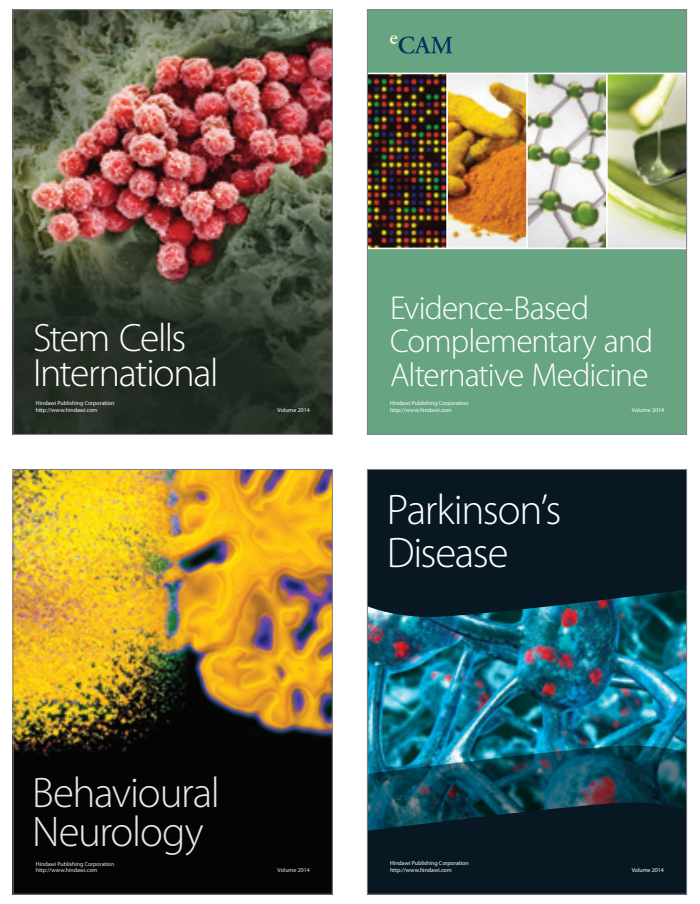
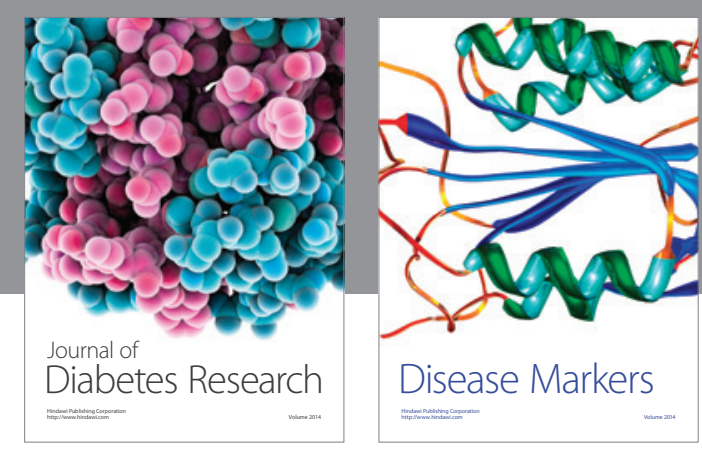

Disease Markers
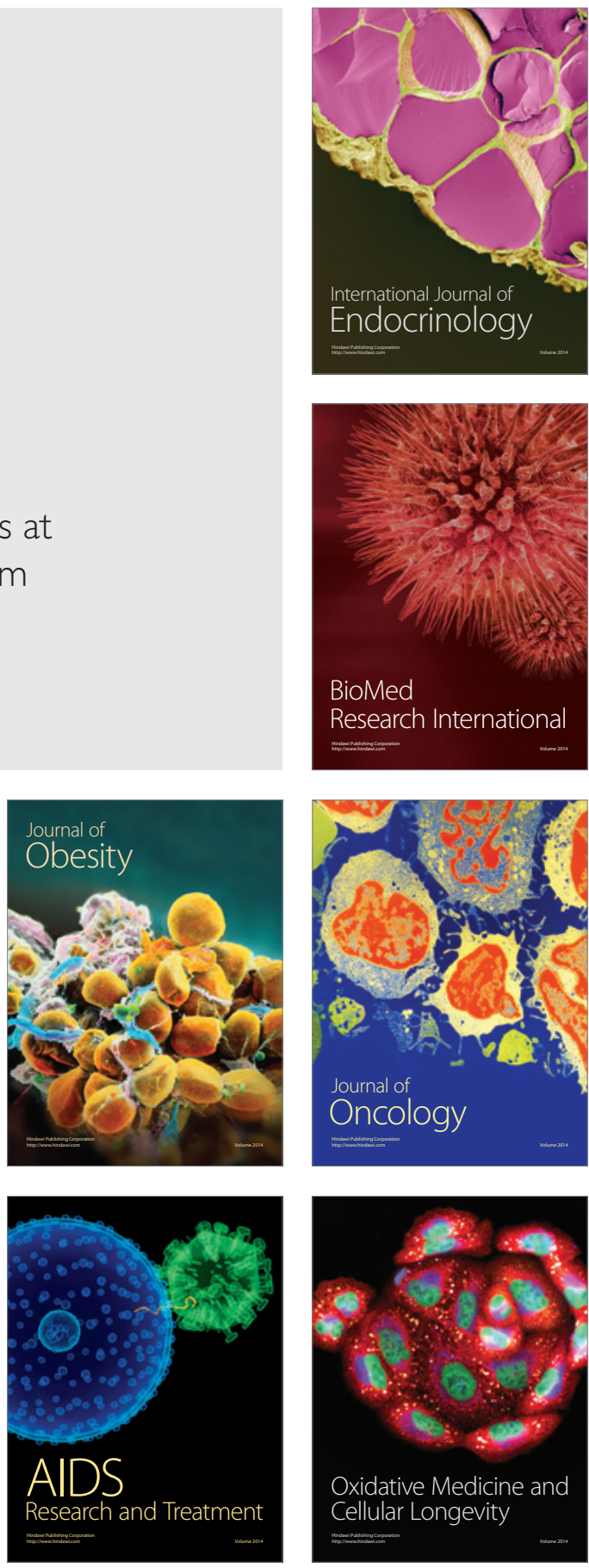